\title{
Single and double stranded DNA binding lymphocytes in the peripheral blood of patients with systemic lupus erythematosus and normal controls
}

\author{
S. SLAVIN AND D. SULITZEANU
}

From the Department of Medicine A and Lautenberg Center for General and Tumor Immunology, Hadassah $\overrightarrow{\vec{H}}$ University Hospital, and Hebrew University, Hadassah Medical School, Jerusalem, Israel

SUMMARY Specific double (D-DNA) and single stranded (S-DNA) deoxyribonucleic acid binding $\omega_{\infty}^{\omega}$ cells were demonstrated in the peripheral blood lymphocytes of patients with systemic lupus ery-o thematosus (SLE) by rosette formation with antigen coated red blood cells. The proportion of DNA binding cells in the peripheral blood of patients with SLE was significantly higher than that found in a 0 random population of healthy individuals. Significant numbers of D- and S-DNA binding lymphocytes were found in patients with active disease even when anti-DNA of fluorescent antinuclear antibodies disappeared. The specificity of the DNA binding cells was confirmed by inhibition $\overbrace{\overparen{D}}$ experiments with D- or S-DNA. Spleen lymphocytes were also examined on one occasion and were 3 found to contain a much higher level of DNA binding lymphocytes than the peripheral blood $\stackrel{\Phi}{-}$ lymphocytes.

Antigen binding cells (ABC) specific for a given antigen have been found in the spleens of animals (reviewed by Ada, 1970; Sulitzeanu, 1971) and in the peripheral blood of immune and of non-immune patients (Hersh and Dyre, 1974). ABC can be demonstrated by autoradiography with labelled antigen (Naor and Sulitzeanu, 1967; Bankhurst and Williams, 1975), by direct or indirect immunofluorescence with fluoresceinated antigen or antibody (Miller et al., 1971) or by rosette formation with antigen coated red blood cells (Hersh and Dyre, 1974; Clark et al., 1972). With the rosette technique lymphocytes from spleens of $N Z B / W_{1}$ female mice were shown to bind specifically single stranded deoxyribonucleic acid (Clark et al., 1972). In the present communication we report the use of a similar technique to demonstrate the presence of $\mathrm{ABC}$ binding single(S-DNA) or double stranded(D-DNA) deoxyribonucleic acid in the peripheral blood of patients with systemic lupus erythematosus (SLE).

\section{Materials and methods}

\section{PATIENTS}

Heparinised peripheral venous blood was collected from 12 patients who met the preliminary criteria Accepted for publication 5 January 1979

Correspondence to S. Slavin, MD, Department of Medicine, A, Hadassah-Hebrew University School of Medicine, Jerusalem, Israel.

of the American Rheumatism Association fô classification as SLE (Cohen et al., 1971) and from 1 . patient with procainamide-induced SLE. Patients were either undergoing treatment or were during remission at the time of venepuncture. On 1 occasion splenic lymphocytes were also examined after the $\vec{\overrightarrow{ }}$ death of 1 of the patients.

\section{LYMPHOCYTES}

Lymphocytes were isolated on a Ficoll-Hypaque gradient (Boyum, 1968) and washed 3 times in cold Hanks's medium. The lymphocytes were suspended in either Tris buffered MEM or Hanks's medium with $5 \%$ fetal calf serum (FCS) at a concentration of $10 \times 10^{6} / \mathrm{ml}$.

DNA

Calf thymus DNA (Calbiochem. Lot 900007) was $\frac{7}{0}$ dissolved in phosphate-buffered saline (PBS), $\mathrm{pH}$ $7 \cdot 3$, at a concentration of $500 \mu \mathrm{g} / \mathrm{ml}$. D-DNA was $\mathrm{N}$ rendered single stranded by boiling for $15 \mathrm{~min} N$ followed by rapid cooling. DNA solutions were kept at $4^{\circ} \mathrm{C}$.

COUPLING OF D-DNA AND S-DNA TO 0 RH POSITIVE RED BLOOD CELLS

The coupling of either D-DNA or S-DNA was carried out according to Clark et al. (1972). $1 \mathrm{ml}$ of D-DNA or S-DNA $(500 \mu \mathrm{g} / \mathrm{ml})$ was mixed with $0.8 \mathrm{ml}$ saline and $0.1 \mathrm{ml}$ chromium chloride $(20 \mathrm{mg} / \mathrm{ml})$. To this 
mixture $0.2 \mathrm{ml}$ of $50 \%$ washed $\mathrm{O} \mathrm{Rh}+\mathrm{RBC}$ was added and mixed thoroughly for $5 \mathrm{~min}$ at room temperature. $5 \mathrm{ml}$ of cold saline was added to stop the reaction, and the cells were washed 4 times in PBS and resuspended in Tris-MEM or Hanks's medium with $5 \%$ FCS at a concentration of $2 \times 10^{8} / \mathrm{ml}$. The presence of coupled DNA was detected by passive haemagglutination with human SLE antiserum to D- and S-DNA: derivatisation was constant with each preparation, as ascertained by haemagglutination titres. A fresh sample of cells was prepared a day or two before each experiment. Donkey RBC were used on some occasions in the same procedures.

\section{ROSETTE-FORMING CELLS (RFC)}

Three sets of tubes were set up in each experiment, each containing a pellet of $10^{6}$ lymphocytes $(0 \cdot 1 \mathrm{ml}$ of the original suspension). $0 \cdot 1 \mathrm{ml}$ PBS was added to the first set and $0.1 \mathrm{ml}$ antigen (D- or S-DNA, $500 \mu \mathrm{g} / \mathrm{ml}$ ) was added to the second and third set, respectively as specificity controls, to saturate the receptors on the lymphocytes. After mixing, the tubes were kept 1 hour on ice, and then $0.1 \mathrm{ml}$ of D- or S-DNA coupled RBC $\left(20 \times 10^{6} \mathrm{RBC}\right)$ were added to each tube (lymphocytes/RBC ratio of $1 / 20$ ), followed by $0.1 \mathrm{ml}$ of medium containing $5 \%$ FCS. The contents of each tube were transferred to small plastic Beckman tubes, centrifuged immediately at $240 \mathrm{~g}$ at $4^{\circ} \mathrm{C}$ for $5 \mathrm{~min}$, and kept at $4^{\circ} \mathrm{C}$ overnight. The cell pellets were gently resuspended with a Pasteur pipette, and an equal volume of $1 \%$ crystal violet containing $10 \%$ FCS and $0.1 \%$ sodium azide was added to stain the lymphocytes. 4000 to 20000 lymphocytes were scanned with a haemocytometer in each test. A rosette-forming cell was defined as a lymphocyte surrounded by at least 4 tightly adhering RBC. Rosette formation by normal or SLE lymphocytes with either autologous or isologous uncoupled RBC were examined as controls by the same technique.

\section{ANTIBODY MEASUREMENTS}

Antinuclear factor was determined by immunofluorescence with acetone-fixed rat liver sections as substrate. Fluorescent sheep antihuman IgG was purchased from Wellcome, England (Lot K9080). Anti-D and S-DNA antibodies were assayed by the microhaemagglutination test with the same coupled $\mathrm{RBC}$ as used for rosette formation. Serum dilutions were started at $1: 6$.

\section{Results}

\section{ANTINUCleAR ANTIBodies}

The titre of fluorescent antinuclear antibodies ranged from 0 to more than $1 / 1600$ (Table 1 ). In the micro- haemagglutination test the titre of D-DNA coated RBC ranged from $1: 6$ to $1: 16$ and the titre of $S$ DNA ranged from $1: 6$ to $1: 100$ (Table 1). Little or no correlation was found between the severity of the clinical manifestations and the antibody titres as measured by either immunofluorescence or haemagglutination (Table 1).

\section{D-DNA A BC}

In SLE patients $0 \cdot 15 \%-4 \cdot 89 \%$ of peripheral blood lymphocytes (mean $1.41 \pm 0 \cdot 40 \%$ ) formed rosettes with D-DNA coupled RBC (Tables 1 and 2). The rosette formation was significantly inhibited by preincubation of the lymphocytes with D-DNA (mean inhibition $70.9 \% \pm 8.2 \%$ ). Lymphocytes of 2 out of 13 patients tested formed rosettes which could not be inhibited by D-DNA. One of these patients had SLE-like syndrome induced by procainamide (patient 8). The other (patient 6) had SLE manifestations which had started atypically at the age of 70 . Preincubation of the lymphocytes (patient 6) with D-DNA resulted in unexplained enhancement of rosette formation. Normal controls had only $0.03 \%-0.66 \%$ D-DNA ABC (mean $0.32 \% \pm 0.1 \%$, and most of these were only moderately inhibited by preincubation with D-DNA (mean inhibition $34 \cdot 2 \% \pm 9 \cdot 8 \%$ ). Both the level and the specificity (percent inhibition) of D-DNA $A B C$ were higher in SLE patients than in normal controls $(P<0.02$ and $P<0.001$ respectively). No correlation was found between the titre of antiD-DNA antibodies and the level of D-DNA ABC (Table 1).

\section{S-DNA ABC}

Rosettes with S-DNA coupled RBC were formed by $0.07 \%-7 \cdot 40 \%$ of peripheral blood lymphocytes (mean 2.08 $\pm 0.38 \%$ (Table 1). Pretreatment of the lymphocytes with S-DNA markedly inhibited the rosette formation (mean inhibition $69.9 \% \pm 6.7 \%$ ) in all except patient 6 , in whom enhancement of rosette formation occurred. In normal controls S-DNA ABC ranged between 0.05\%-1.01\% (mean $0.29 \pm 0.11 \%$ ) with lower inhibition by pretreatment with S-DNA (mean inhibition $35.6 \%$ $\pm 8 \cdot 3 \%$ ). The level of S-DNA ABC was significantly higher in SLE than in normal controls $(P<0.01)$. No correlation was found between the titre of anti-S-DNA antibodies and the level of S-DNA ABC (Table 1).

Several experiments were carried out to obtain some information on a number of variables which might possibly affect the results of the rosette tests, such as (1) variability within replicates, (2) effect of carrier red cell (donkey versus human), and (3) variability within lymphocyte samples taken at 
Table 1 Haemagglutinating antibodies were assayed by means of D-DNA or S-DNA coupled red blood cells. ABC were studied by rosette formation. Specificity of rosettes was determined by pretreating the lymphocytes with soluble $D$ or $S-D N A$ before formation of rosettes

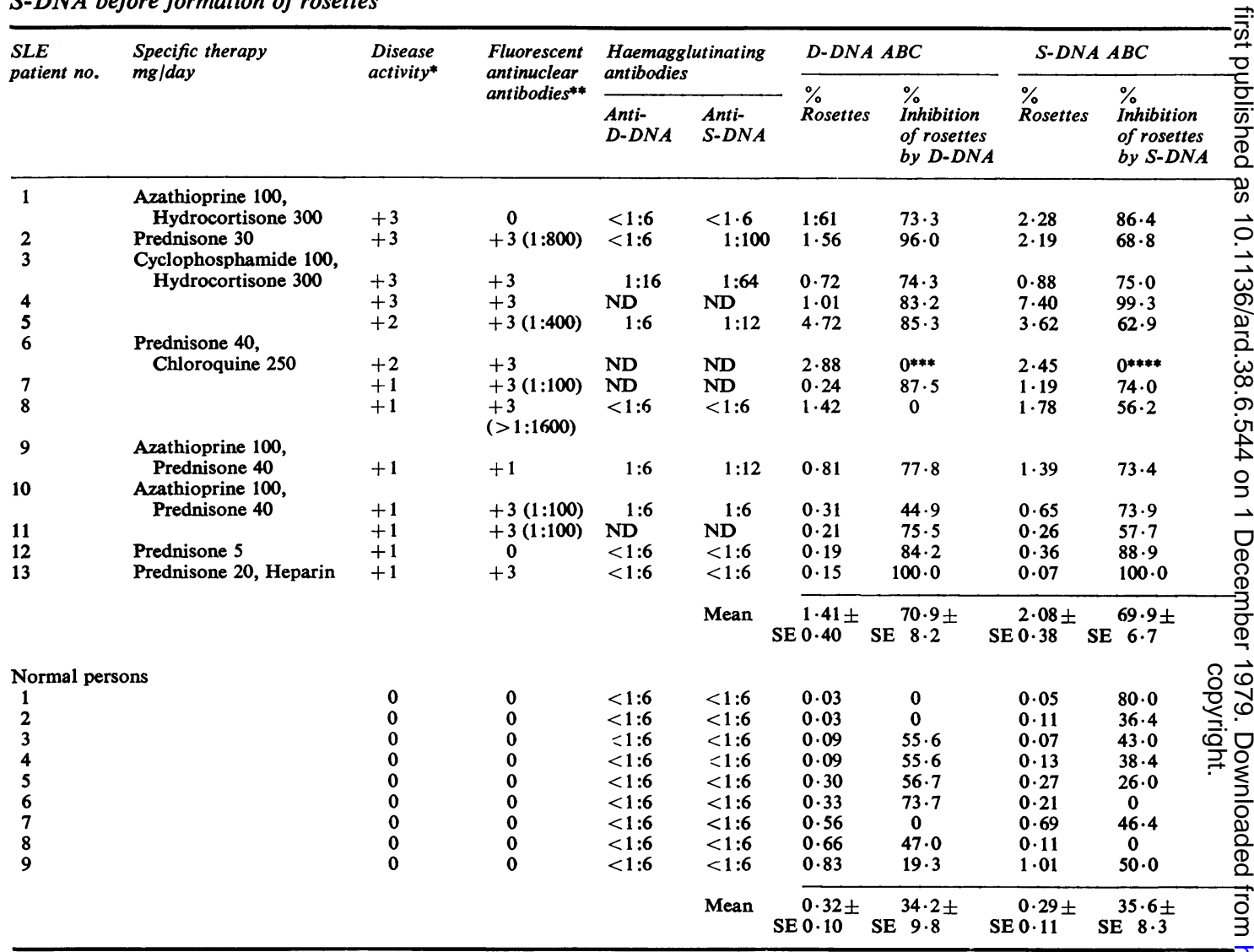

$\mathrm{ND}=$ Not done. ${ }^{*}$ Grading from 0 to $+3 .{ }^{* *}$ Qualitative grading from 0 to $+3 .{ }^{* * *}$ Rosette formation increased to $5 \cdot 02 \% .{ }^{* * *} \mathbf{R o s e t t e}$ formatio increased to $3 \cdot 19 \%$.

Table 2 Rosettes were formed with human $(O \mathrm{Rh}+)$ or donkey red blood cells coupled with $D$ or S-DNA. Blood samples were taken at dates shown

\begin{tabular}{lllll}
\hline Patient no. & Date 1976 & $\begin{array}{l}\text { Carrier } \\
\text { RBC }\end{array}$ & $\begin{array}{l}\% \text { D-DNA } \\
A B C\end{array}$ & $\begin{array}{l}\% \text { S-DNA } \\
A B C\end{array}$ \\
\hline 1 & 5 Dec. & Donkey & 0.67 & 2.43 \\
& 5 Dec. & Donkey & & 1.93 \\
& 12 Dec. & Donkey & 2.26 & 2.55 \\
& 16 Dec. & O Rh+ & & 2.40 \\
5 & 16 Dec. & O Rht & & 2.10 \\
& 27 Dec. & O Rht & 4.89 & 4.57 \\
2 & 31 Dec. & O Rht & 4.56 & 2.68 \\
& 27 Dec. & O Rht & 1.75 & 2.31 \\
& 31 Dec. & O Rht & 1.41 & 2.08 \\
\hline
\end{tabular}

different times from a given patient. As shown in Table 2 the results were usually unaltered by any of these variables. In addition, no inhibition of $D$ - and S-DNA ABC could be obtained by preincubating the cells with an unrelated protein like bovine or human serum albumin.

CORRELATION BETWEEN CLINICAL ACTIVITY OF SLE AND D-SNA AND S-DNA ABC

Table 1 shows that the level of D-DNA usually? correlated with the level of S-DNA ABC. AIG patients with clinically active SLE had significan levels of D-DNA and S-DNA ABC in the periphera blood, though some of these patients had neithef demonstrable fluorescent antinuclear antibodies nor significant titre of anti-D-DNA or S-DNA antic bodies (Table 1) at that particular stage.

D-DNA AND S-DNA ABC IN THE SPLEEN

Spleen lymphocytes were examined on one occasior immediately after one of the patients died (patient 3 ? 
Table 1). The number of D-DNA and S-DNA ABC was strikingly high ( $4.08 \%$ and $9.43 \%$, respectively). Specificity of these $\mathrm{ABC}$ was ascertained by significant blocking of rosette formation by preincubation of the splenocytes with the appropriate antigen $(88.5 \%$ and $73.5 \%$ rosette inhibition, respectively). It is interesting to note that 8 days before her death $\mathrm{ABC}$ in the peripheral blood was much lower $(0.72 \%$ for D-DNA and $0.88 \%$ for S-DNA, Table 1).

\section{Discussion}

The results show that specific D-DNA and S-DNA binding lymphocytes can be demonstrated in the peripheral blood of patients with SLE. The number of S-DNA and D-DNA binding lymphocytes in the blood ranged between $0.07 \%$ and $7.40 \%$ and between $0.15 \%$ and $4.89 \%$, respectively. Normal, peripheral blood lymphocytes showed significantly lower specific DNA binding, as suggested by the lower percentage of DNA $\mathrm{ABC}$ on the one hand ( $\mathrm{P}<0.02$ for D-DNA; $\mathrm{P}<0.001$ for S-DNA) and by the less effective inhibition of rosette formation after preincubation with the appropriate DNA on the other $(P<0.01$ for both $D$ and S-DNA).

The specificity of the DNA binding was confirmed by the inhibition tests with D- and S-DNA. Rosette formation was significantly inhibited by preincubating the lymphocytes of SLE patients with the appropriate antigen (mean inhibition of D-DNA $70.9 \% \pm 8.2 \%$, mean inhibition of S-DNA $69.9 \%$ $\pm 6.7 \%$ ). The presence of inhibitable D-and S-DNA $\mathrm{ABC}$ in the normal controls suggests it is possible that specific DNA $\mathrm{ABC}$ do exist in healthy individuals.

Although rosettes formed by SLE lymphocytes were very likely due to true antigen specific receptors, one cannot disregard the possibility that cytophilic anti-DNA antibodies, or DNA-anti-DNA complexes attached to $\mathrm{Fc}$ receptors, or both, might have enhanced the number of rosettes. However, previous studies have shown that cytophilic antibodies were unlikely to be involved in $\mathrm{ABC}$ determinations in both patients with thyroiditis (Perrudet-Badoux and Frei, 1969) and mice (Naor and Sulitzeanu, 1969). Cytophilic antibodies or antigen-antibody complexes were unlikely to be involved in rosette formation by normal lymphocytes, as none of the normal donors had detectable antinuclear antibodies (by fluorescence and haemagglutination).

Since only one-third of the normal DNA ABC -ould be inhibited by DNA, it seemed reasonable ...at most of the normal $\mathrm{ABC}$ were reacting with . me membrane component of the RBC rather than th the DNA coating it. This was confirmed by the finding of lymphocytes rosetting with untreated allogenic and even autologous RBC in both normal persons and SLE patients. However, these rosettes could not be inhibited by either D or S-DNA nor by other unrelated proteins like BSA (Slavin and Sulitzeanu, unpublished). Lymphocytes which can bind self components of the RBC membrane have already been described in mice (Siegel and Sherman, 1972), rabbits (Baxley et al., 1973), and man (Dewar et al., 1974; Bankhurst and Williams, 1975.)

DNA ABC have been found in NZB/WF female mice which develop an autoimmune disease similar to SLE, with antinuclear antibodies. With the same rosette formation technique $1 \cdot 3 \%-8 \cdot 5 \%$ of the mononuclear spleen cells showed binding of S-DNA coated to sheep RBC. In these experiments, too, $0 \cdot 38 \%-2 \cdot 0 \%$ of the splenocytes rosetted with normal uncoated sheep RBC (Clark et al., 1972).

Native DNA ABC in SLE was demonstrated by autoradiography with ${ }^{125}$ I labelled DNA (Bankhurst and Williams, 1975). The incidence of DNAbinding lymphocytes was $0.40 \pm 0.273$ in 12 patients with active SLE in contrast to $0 \cdot 120 \pm 0.048$ and $0.048 \pm 0.036$ in 12 patients with inactive SLE and in normal persons, respectively.

In this study the incidence of DNA binding determined by rosetting was in the same range and occasionally higher. The difference may be due either to higher sensitivity of rosetting techniques as an indicator of DNA $\mathrm{ABC}$ or more likely to some interactions of the red cell membrane and macromolecules with lymphocyte receptors.

$\mathrm{ABC}$ specific for other antigens have also been studied in human peripheral blood lymphocytes by their ability to form rosettes with antigencoated RBC. After immunisation with the protein antigen Keyhole limpet haemocyanin (KLH) $0 \cdot 30 \%$ $7 \cdot 20 \%$ of normal peripheral blood lymphocytes formed rosettes with KLH-coated RBC. There were $0.02 \%-0.24 \%$ rosette-forming cells in the nonimmune individuals (Hersh and Dyre, 1974). Rosette formation was also studied in human and experimental thyroiditis, which are good models of true autoimmune disorders (Perrudet-Badoux and Frei, 1969). In human thyroiditis $0 \cdot 15 \%-9 \cdot 8 \%$ of peripheral blood lymphocytes rosetted with thyroglobulin-coated sheep red blood cells, whereas only $0.05 \%-0.4 \%$ rosettes were demonstrated in other thyroid diseases. The rosettes could be inhibited by methotrexate. Thyroglobulin receptors were shown to appear after preincubation with trypsin. The number of rosettes did not correlate with the titre of circulating antibody, and the clinical picture correlated better with the rosette formation than with humoral antibodies (Perrudet-Badoux and Frei, 1969). 
The finding of high levels of D-DNA and S-DNA binding lymphocytes in SLE patients even during immunosuppressive therapy despite negative antinuclear antibodies (by immunofluorescence and haemagglutination) might be important. In autoimmune diseases the titration of circulating antibody is known to be of little diagnostic or prognostic value. However, in SLE, which is s classical immune complex disease, DNA-anti-DNA complexes play a major role in the pathogenesis of the vascular manifestations, predominantly the kidney. Therefore a decreasing titre of antinuclear antibodies is usually considered as an important parameter for evaluating the efficiency of the therapeutic means and/or remission. Nevertheless, many patients (case 1 being an example) deteriorate despite improvement of the laboratory parameters of disease, including the titre of antinuclear antibodies. As shown in this study, DNA binding lymphocytes can be demonstrated even when no anti-DNA antibody is detectable. It seems therefore that these ABC might be the memory cells for anti-DNAproducing lymphoplasmocytes. Quantitations of DNA-binding lymphocytes during various stages of SLE and in relation to therapy should be carried out to evaluate their possible prognostic implications. Maximal 'knock-out 'of anti-DNA memory cells with DNA $\mathrm{ABC}$ as a marker might be essential in order to achieve better remission in SLE.

Another point of interest was the finding of a much higher level of D- and S-DNA ABC in the spleen than in the blood of one SLE patient $(4.1 \%$ of D-DNA ABC and $9.4 \%$ of S-DNA ABC in the spleen versus $0.72 \%$ and $1.38 \%$ in the blood, respectively). These data would suggest a role for the spleen as a potential reservoir of committed, activated lymphocytes in SLE. Further studies of SLE at the cellular level might contribute to better understanding of the disease.

We are greatly indebted to Dr A. Braverman, Mrs R. Levy, and $\operatorname{Dr}$ A. Zlotnick for supplying sera of SLE patients of SLE patients and for assaying for antinuclear activity by immunofluorescence, and to Dr H. R. Holman for reviewing the manuscript.

\section{References}

Ada, G. L. (1970). Antigen-binding cells in tolerance and immunity. Antigen binding lymphocyte receptors. Transplantation Reviews, 5, 105-129.

Bankhurst, A. D., and Williams, R. C., Jr. (1975). Identification of DNA-binding lymphocytes in patients with systemic lupus erythematosus. Journal of Clinical Investi-음 gation, 56, 1378-85.

Baxley, G., Bishop, G. B., Cooper, A. G., and Wortis, H. H. (1973). Rosetting of human red blood cells to thymocytes and thymus-derived cells. Clinical and Experimentales Immunology, 15, 385-392.

Boyum, A. (1968). Isolation of mononuclear cells and granu-. locytes from human blood. Scandinavian Journal of Clinical $\overrightarrow{-\overrightarrow{+}}$ and Laboratory Investigation, 21, (Suppl. 97), 77-89.

Clark, C., Bell, D. A., and Vaughan, J. H. (1972). Anti-DNA plaque-forming cells (PFC) and rosette-forming cells (RFC) in spleens of NZB/WF female (B/W mice. Journal of Immunology, 109, 1143-1145.

Cohen, A. S., Reynolds, W. E., Franklin, E. C., Kalker, J. P., ఠ) Ropes, M. W., Shulman, L. E., and Wallace, S. L. (1971). Preliminary criteria for the classification of systemic lupus + erythematosus. Bulletin on Rheumatic Diseases, 21, 643-음 648.

Dewar, A. E., Stuart, A. E., Parker, A. C., and Wilson, C. $\vec{\square}$ (1974). Rosetting cells in autoimmune haemolytic anaemia. Lancet, 2, 519-520.

Hersh, E. M., and Dyre, S. E. (1974). Cells binding the $\frac{1}{3}$ antigen keyhole limpet hemocyanin in the peripheral blood and in the lymphocyte cultures of non-immune and immunised human subjects. Clinical and Experimengal $\vec{c}$ Immunology, 17, 299-309.

Mille1, A., DeLuca, D., Decker, J., Eggel, R., and Sercars, E. E. (1971). Specific binding of antigen to lymphocyf American Journal of Pathology, 65, 451-465.

Naor, D., and Sulitzeanu, D. (1967). Binding of radioiodinated bovine serum albumin to mouse spleen cells. Nature, 214, 687-688.

Naor, D., and Sulitzeanu, D. (1969). Affinity of radio- $\varrho$ iodinated bovine serum albumin for lymphoid cells. $\overrightarrow{\vec{D}}$ Israel Journal of Medical Sciences, 5, 217-229.

Perrudet-Badoux, A., and Frei, P. C. (1969). On the mechanism of rosette formation in human and experimental thyroiditis. Clinical and Experimental Immunology, 5, 117-127.

Siegel, I., and Sherman, W. B. (1972). The interaction of lymphocytes with autologous red cells. Journal of Allergy and Clinical Immunology, 50, 65-74.

Slavin, S., and Sulitzeanu, D. (Unpublished). Rosette formation by peripheral blood lymphocytes of SLEC patients and normal controls with autologous and allogeneic RBC. Manuscript in preparation.

Sulitzeanu, D. (1971). Antibody-like receptors on immunocompetent cells. Current Topics in Microbiology and Immunology, 54, 1-18. 